\title{
A negociação da moralidade por meio da produção de justificativas na reconstrução da narrativa do abuso sexual de crianças e de adolescentes: um estudo situado ${ }^{1}$
}

\section{The negotiation of morality through the production of justification in the child and adolescent reconstruction of the narrative of sexual abuse: a situated study}

Mariléia Sell*

Universidade do Vale do Rio dos Sinos

Novo Hamburgo - Rio Grande do Sul / Brasil

\begin{abstract}
RESUMO: Esta pesquisa, ancorada nos preceitos teóricos da Etnometodologia (GARFINKEL, 1967) e da Análise da Conversa (SACKS, 1992) estuda qualitativamente interações entre um conselheiro tutelar e crianças e adolescentes vítimas de abuso sexual. O objetivo é observar como a experiência do abuso é significada e realinhada com as expectativas morais e sociais (BERGMANN, 1998). A análise das interações mostra que os adolescentes realizam um trabalho moral defensivo de forma mais ativa (DREW, 1988), enquanto as crianças se engajam menos neste tipo de atividade. Esse dado indica que os adolescentes possivelmente se orientam para o paradoxo da vitimização e da culpabilizaçăo das vítimas de abuso sexual (SANTOS, 2003), demonstrando maior socialização sobre como narrar histórias com implicaçôes morais e sobre como performar a vítima "ideal" (TRINCH, 2013).
\end{abstract}

PALAVRAS-CHAVE: fala-em-interação; Etnometodologia; abuso sexual infantil; justificativas; moralidade.

*marileiasell@unisinos.br

${ }^{1}$ Este artigo é resultante da tese de doutorado "Significando o abuso sexual infantil na fala-em-interação: estratégias interacionais acionadas por conselheiro tutelar e crianças na reconstrução da narrativa do abuso", defendida pela autora em janeiro de 2013 e orientada pela Prof. Dr. Ana Cristina Ostermann, do Programa de Pós Graduação em Linguística Aplicada, da Universidade do Vale do Rio dos Sinos- Unisinos. 


\begin{abstract}
This study, based on the theoretical principles of Ethnomethodology (GARFINKEL, 1967) and Conversation Analysis (SACKS, 1992), is a qualitative investigation of spoken interactions between a Child Protective Services officer and sexually abused children or adolescents. The aim is to observe how the experience of the abuse is signified and realigned according to moral and social expectations (BERGMAN, 1998). The analysis of the interactions shows that adolescents invest more in moral defense (DREW, 1988), while children display weaker engagement in this type of activity. These data reveal that adolescents probably guide themselves toward the paradox of victimization and culpability displayed by victims of sexual abuse (SANTOS, 2002), showing a higher degree of socialization concerning the activity of narrating stories with moral implications and the ability of performing the "ideal" victim (TRINCH, 2013).
\end{abstract}

KEYWORDS: talk-in-interaction; Ethnomethodology; child sexual abuse; justification; morality.

\title{
1 Introdução
}

\subsection{A produção de justificativas para a manutenção da ordem social e moral}

As pessoas se orientam tacitamente para as regras sociais, demonstrando um saber compartilhado do mundo. Essas regras são inteligíveis, descritíveis, analisáveis e racionais, ou seja, elas são accountable, ou justificáveis, muito embora as pessoas não estejam conscientes desse caráter reflexivo de suas ações. A accountability, explicabilidade ou prestação de contas, na tradução sugerida por Garcez (2008, p. 27), é o foco central de análise da Etnometodologia (COULON, 1995). Ou seja, a Etnometodologia se ocupa com os métodos empregados pelas pessoas para reforçar as práticas culturais que mantêm a "integridade do sistema" (FETTERMAN, 1998, p. 17).

A Análise da Conversa (AC) compartilha do interesse da Etnometodologia em analisar os métodos usados pelas pessoas para produzir e reconhecer a ordem social. Assim, a AC e a Etnometodologia buscam entender como as pessoas "fazem" a vida social e como a vida social, que parece tão objetiva, estável e perene é, na verdade, alcançada e gerenciada através de ações locais e situadas. Isso equivale a dizer que o processo constante de construção do mundo é um empreendimento interacional e que as justificativas desempenham a função de tornar o mundo visível e descritível.

Autores como Garcez (2008), Almeida (2009) e Del Corona (2011) optam por manter o termo account em seu original em inglês, assumindo 
a dificuldade de traduzi-lo para a língua portuguesa sem prejuízos à gama de ações que podem ser realizadas por meio dessa estratégia linguísticointeracional. Apesar de manter o termo account, Garcez (2008) sugere uma possibilidade de tradução para a língua portuguesa, qual seja, prestação de contas. Como veremos mais adiante, uma das ações desempenhadas pelos accounts é o provimento de justificativas e, por ser essa a ação mais recorrente encontrada nos dados desta pesquisa, opto, assim como Ostermann e Carvalho (2012), por este termo (i.e. justificativas).

Antes de tornar-se tópico de análise da Etnometodologia, os sociólogos já se ocupavam com o fenômeno da produção de justificativas e a sua relação com a conduta socialmente desviante. Em meados do século passado o sociólogo Wright Mills (1940) publicou seu trabalho "Situated Actions and Vocabularies of Motive", em que analisa o papel da produção dos "motivos" em situaçôes sociais ordinárias. Para o autor, os "vocabulários de motivos" são instrumentos sociais solicitados ou ofertados quando alguma expectativa de ação é frustrada. Nessas situações, a função dos motivos não é a de desculpar a ação realizada, mas de alinhá-la com as expectativas e normas sociais e morais, desempenhando um trabalho essencialmente reconciliador. Mills (1940), a exemplo do que postula a Análise da Conversa e a Etnometodologia, desloca o estudo dos comportamentos linguísticos da esfera individual para a esfera social, ou seja, as ações dos atores sociais (em esferas microinteracionais) tornam possível a interpretação da conduta social (em esferas macrossociais). Para ele "as diferentes razões que as pessoas dão para suas açōes não são elas próprias desprovidas de razões” (1940, p. 904).

Dentro do mesmo escopo de pesquisa, Scott e Lyman (1968) se debruçam sobre a função conciliatória do uso da linguagem, que eles passam a chamar de accounts. Em situaçôes de potencial "ameaça à face" (GOFFMAN, 1959), as justificativas assumem a função de restaurar o equilíbrio social. Para Scott e Lyman (1968), as justificativas têm a habilidade de "sustentar as vigas de uma associação rachada; estabelecer pontes entre o prometido e o executado, consertar o quebrado e conciliar o apartado" ${ }^{2}$ (p. 46). Os autores ainda definem as justificativas como uma "ferramenta linguística empregada sempre que uma ação é objeto de questôes valorativas" (1968, p. 46). Essas ferramentas linguísticas são, assim, cruciais, para a

\footnotetext{
${ }^{2}$ Tradução livre da autora.

${ }^{3}$ Tradução livre da autora.
} 
manutenção da ordem social, pois podem evitar o surgimento de conflitos ou resolvê-los, caso surjam.

Para Scott e Lyman $(1968 ; 1990)$ os atores sociais não provêm justificativas quando estão engajados em comportamentos que não quebram as expectativas morais. Ao contrário, as justificativas são acionadas quando um ator social quer "explicar um comportamento não esperado ou inconveniente" (p. 220). Nesse sentido, fica evidente a relação entre a ocorrência de justificativas e o "trabalho moral defensivo" (DREW, 1998).

Desculpas e justificativas são as duas classificações de accounts apontadas por Scott e Lyman (1990). As justificativas, segundo os autores, são providas quando a pessoa aceita a responsabilidade pela ação em questão, mas nega a qualidade negativa associada à ação. Elas funcionam, então, como um "vocabulário socialmente aprovado que neutraliza uma ação" (p. 219). Em outras palavras, ao prover justificativas, o autor reconhece que determinada ação não é permitida (e.g. matar), mas reivindica que dada ocasião específica permitia ou até requeria a ação (e.g. autodefesa).

Nessa linha das ações neutralizadas por meio de um vocabulário socialmente aprovado, os autores exemplificam as técnicas utilizadas pelas pessoas para essa empreitada interacional: a) alegar que determinada ação não causou mal a ninguém; b) alegar que a vítima mereceu determinada ação; c) alegar que outros também realizaram determinada ação e que não sofreram punição e d) alegar que agiu em lealdade à outra pessoa, a quem o autor devia favores. Além desses quatro "vocabulários", Scott e Lyman (1990) acrescentam ainda outros dois, que funcionam para neutralizar açōes: a) contar histórias tristes (e.g. passado miserável, que explicaria o presente estado do autor) e b) apelar para a autorrealização (e.g. usar drogas para expandir a consciência).

Já as desculpas (SCOTT; LYMAN, 1990) são accounts acionados pelos atores sociais para admitir que determinada ação é ruim ou errada, mas negar a total responsabilidade por ela. São, então, "vocabulários socialmente aprovados de mitigação ou de minimização de responsabilidade" (p. 220): a) apelar para acidentes (acidentes são aceitos porque podem acontecer a qualquer um e porque são esporádicos, motivo pelo qual o autor não pode apelar com frequência para esse vocabulário; b) apelar para o desconhecimento de algo (e.g. "eu não sabia o que isso significava") ou, então, apelar que agiu sob coerção; c) apelar para impulsos biológicos (e.g. ela me seduziu e eu não consegui resistir) e d) apelar para um "bode expiatório", ou seja, atribuir a ação "errada" como uma resposta à ação de outra pessoa. 
Considerando os accounts como um "vocabulário" de domínio social e não residente na mente do indivíduo, os atores sociais são responsabilizados pela produção de justificativas apropriadas para cada situação. Levando a ideia de vocabulários a um extremo, Scott e Lyman (1990) acreditam que a incapacidade de produzir accounts (com todas as açôes que desempenham) de forma situada e em conformidade com as expectativas culturais pode ser interpretada inclusive como um indício de doença mental. Ainda, uma justificativa é considerada ilegítima quando as razões para determinada ação não conseguem "normalizar" as expectativas socialmente validadas (SCOTT; LYMAN, 1968; 1990) (e.g. um encarregado de enforcar pessoas condenadas à morte, para não sofrer sanções sociais, pode falar da sua atividade como um compromisso, mas não se referir à atividade como um prazer).

Na próxima seção abordo a temática dos accounts sob uma perspectiva etnometodológica, de cunho interacional. Essa abordagem, como veremos, transcende o modelo de "vocabulários" para uma compreensão mais situada e local.

\subsection{0 caráter situado da produção de justificativas}

Avançando na proposta de estudos de Scott e Lyman, os analistas da conversa passam a olhar para o fenômeno da produção de accounts em uma perspectiva etnometodológica e com dados naturalísticos. Assim, autores como, Firth (1995), Drew (1998), Stokoe (2003), Ostermann e Carvalho (2012), Carvalho (2012), Robinson e Bolden (2010), Del Corona (2011), De Fina (2009) e Van de Mieroop (2011), analisam o contexto de produção dos accounts e as ações que realizam na sequencialidade da interação. $\mathrm{O}$ caráter situado dessa abordagem mostra, então, que a produção de accounts é um empreendimento colaborativo "iminentemente dialógico" e "altamente negociado" (DE FINA, 2009), o que inviabiliza o seu encapsulamento em um "vocabulário" predefinido, como proposto por Scott e Lyman (1990).

Como já vimos, um conceito-chave para a Etnometodologia é a explicabilidade (accountability). A sociedade é mantida e produzida através das descrições, explicações e justificativas (accounts) que os membros de determinada cultura fornecem para as suas ações cotidianas. Em outras palavras, são habilidades de raciocínio de senso comum, através das quais os atores produzem e reconhecem as suas ações. Os estudos e experimentos de Garfinkel (1967) demonstram como os atores sociais atingem uma apreensão compartilhada e intersubjetiva do mundo social. Para o autor, são os métodos 
comuns de raciocínio que tornam possível um mundo social compartilhado. Os seus experimentos apontam para a exigência do provimento de accounts por parte daqueles que não se alinham com comportamentos sociais tidos como cotidianos. Esses accounts funcionam, assim, como uma maneira de tornar esses comportamentos inteligíveis e moralmente aceitos, sempre de acordo com entendimentos implícitos e compartilhados pelos membros. Neste processo, é imprescindível levar em consideração que os membros do mundo social são agentes que se tratam mutuamente como pessoas que devem responder por suas ações. É justamente essa atribuição recíproca de responsabilidade pelo comportamento que Bergmann (1988; 2002) chama de protomoralidade: o princípio básico da moralidade (STIVERS; MONDADA; STEENSIG, 2011).

Maynard (1984) e Firth (1995) demonstram que as pessoas se valem da estratégia dos accounts não apenas para restaurar expectativas frustradas, mas também como um método criativo e proativo para estabelecer acordos e resolver problemas. Analisando a interação entre um comprador e um vendedor de queijos, Firth mostra a natureza compartilhada (i.e. não apenas como um empreendimento unilateral) da produção de accounts, como um esforço para atingir o entendimento mútuo e efetuar a negociação. Nesse sentido, ao mesmo tempo em que os accounts tornam pública a natureza do conflito, eles proveem recursos para a negociação e resolução dele.

O reconhecimento ou a antecipação de possíveis desalinhamentos interacionais, como, por exemplo, discrepância de preços, discussão de prazos, negociação de despesas com transporte e taxas cambiais, significam o reconhecimento e a antecipação do desalinhamento entre cultura (regras sociais do comércio) e conduta (posicionamento individual frente às regras do comércio). As práticas sociais usadas para evitar ou reparar essas situações são, então, práticas de reestabelecimento da cultura e de imposição da ordem social (SEMIN; MANSTEAD, 1983). Firth (1995) aponta que as justificativas tornam visíveis (logo, contestáveis) as percepçôes de "normal" e "justo" dos participantes, ao invocarem fatos, normas e regras da instituição "comércio". Assim, a produção de accounts torna a instituição "comércio" localmente reconhecível, ou justificável, no turno a turno da interação.

Também em uma perspectiva interacional, Stokoe (2003) mostra como moradores de um mesmo bairro produzem accounts sobre suas atividades e identidades em um programa de televisão destinado a resolver conflitos entre vizinhos. Para Drew (1998), todas as relações e condutas 
sociais são um fenômeno explicável, pois nas práticas de relatar, descrever e raciocinar reside o papel central da linguagem na construção da realidade social. Assim, ao produzir accounts, as pessoas se orientam para a ordem social reguladora do que significa "ser vizinho" (i.e. não fazer muito barulho, não ter uma vida promíscua etc.). Ao se engajar em atividades moralmente orientadas, como, por exemplo, descrever ou julgar os outros, o falante, ao mesmo tempo, reflete e produz a realidade moral. Quando as pessoas contam histórias sobre os outros e sobre si mesmas, elas se engajam em um trabalho de "alinhar e realinhar a ordem social e moral" (GOODWIN, apud STOKOE, 2003, p. 320) e reconstruir constantemente o que define um comportamento adequado e moral.

Por meio da abordagem teórico-metodológica da Análise das Categorias de Pertença (ACP) (SACKS, 1992), Stokoe (2003) mostra como os atributos "naturais" da maternidade, família e relacionamentos entre adultos são socialmente construídos e mantidos na ação de produzir accounts. A "naturalidade" é mantida dentro de limites morais e quem age em desacordo com essas normas culturalmente compartilhadas tem grandes chances de ser julgado como imoral. Nessa perspectiva, Stokoe mostra como certas práticas discursivas ajudam na manutenção do "mundo social generificado" (p. 332), ou seja, como a seleção de determinadas categorias, ao invés de outras, pode desempenhar um trabalho de avaliação moral. Quando determinadas categorias (e.g. mãe, esposa) não seguem as normas que governam o comportamento tido como apropriado para as mulheres, elas podem sofrer avaliações morais depreciadoras, justamente pelas atribuições das diferentes categorias sociais serem culturalmente compartilhadas pelos membros.

Evidentemente, em uma perspectiva interacional, é preciso analisar a invocação dessas categorias e suas atribuições de forma sequencial e situada, pois, ao passo que a categoria social "mulher solteira", pode, por exemplo, suscitar julgamentos negativos em determinadas situaçóes, também pode, em outras, ser acionada para angariar simpatia ou condescendência (STOKOE, 2003). Assim, temos construçóes reguladoras desde como a mulher deve se comportar sexualmente (i.e. não fazer barulho durante as atividades sexuais), como deve ser a sua aparência (i.e. não ser gorda), como deve desempenhar a maternidade (i.e. não deixar as crianças fazerem muito barulho para não perturbarem os vizinhos), entre outras, para manter uma "feminilidade viável” (NILAN, 1995, apud STOKOE, 2003). Nesse sentido, para Stokoe, 
as práticas normativas e generificadas são mantidas por meio da ação de categorizar, nas rotinas interacionais da vida social e, para a autora, quanto mais naturalizadas, mais poderosas elas são. Para Maynard (2003), através das relaçôes de normalidade e anormalidade que as pessoas estabelecem entre as categorias e as atividades correspondentes, é possível perceber o raciocínio do senso comum sobre o mundo social.

\subsection{Para além da sequencialidade}

Embora a sequencialidade seja uma premissa basilar da Análise da Conversa, Ostermann e Carvalho (2012) mostram que existe um tipo de account que não pode ser entendido e descrito somente com base no sistema de tomada de turnos (SACKS; SCHEGLOFF; JEFFERSON, 1974). As autoras analisam interações entre atendentes e usuárias do Disque Saúde e percebem que muitas das mulheres que utilizam esse serviço público se engajam no provimento de justificativas não demandadas interacionalmente, ou seja, não solicitadas pelas atendentes e não relevantes sequencialmente para a ação em curso. Então, mais do que se orientar apenas para a sequencialidade da interação, essas mulheres realizam um intenso trabalho moral e de salvamento da face (GOFFMAN, 1959; ARUNDALE, 2010; 2006; LERNER, 1996; SAMRA-FREDERIKS, 2010), antecipando possíveis avaliações negativas por parte do interlocutor.

Assumindo que através dos accounts os interlocutores realizam diferentes açôes, Buttny (1993) sugere três frentes de análise para a sua produção: a) preservação da face dos interagentes; b) manutenção das relações sociais e c) controle social. Para o autor, a preservação da face (GOFFMAN, 1959; ARUNDALE, 2010) é a ocorrência mais citada na literatura. Face é a imagem positiva que as pessoas reivindicam para si para obter a aprovação por parte dos outros, porém, mais do que isso, ela é um empreendimento altamente negociado na interação, o que lhe dá um caráter social e não individual. Uma situação de perda da face pode causar sensações de embaraço e insegurança, trazendo prejuízos à reputação.

Na segunda função, conforme Buttny (1993), os accounts são utilizados para "lubrificar" as relaçôes sociais, na medida em que reconciliam o comportamento tido como socialmente e moralmente problemático. Já a terceira função, do controle social, revela o quanto as pessoas se orientam e respondem às regras sociais. Dessa forma, através do estudo dos accounts é possível ter acesso às múltiplas crenças, normas morais e práticas culturais 
implícitas na sua produção. Em outras palavras, a ordem moral emerge nas descrições que os atores fazem das diferentes atividades sociais e no valor que atribuem a essas atividades (i.e. legítimas ou ilegítimas).

De acordo com as discussões feitas até aqui, podemos ver o papel que os accounts desempenham na organização das ações cotidianas dos atores sociais. Ao fornecer explicações sobre suas ações (discursivas ou não), as pessoas se orientam para possíveis "infrações" de ordem moral (BERGMANN, 1998; 2002). Nesse sentido, um estudo sobre como e onde ocorrem (ou não) os accounts na sequencialidade das interações entre conselheiro tutelar e crianças e adolescentes vítimas de abuso sexual, possibilita o acesso às falas do senso comum sobre o fenômeno do abuso sexual. Ainda, é possível aprofundar o entendimento de socialização das crianças como um fenômeno intrinsecamente interacional (SCHIEFFELIN; OCHS, 1986).

\section{Metodologia}

Por seu compromisso êmico, a pesquisa demanda uma abordagem que dê conta dos sentidos produzidos pelos interagentes e não os da pesquisadora. $\mathrm{O}$ corpus desta pesquisa consiste de quatro excertos, de um total de 50 interações, gravadas e transcritas de acordo com o sistema de transcrição elaborado por Gail Jefferson (1984) e adaptado por Schnack, Pisoni e Ostermann (2005), constante na seção de Apêndices. A gravação dos dados em áudio é um recurso que permite um tratamento exaustivo das interações, além de facultar a análise por outros pesquisadores. Os dados foram obtidos durante a incursão etnográfica da pesquisadora (COULON, 1995; O'REILLY, 2009), que acompanhou, por dois anos, as visitas domiciliares do conselheiro tutelar participante desta pesquisa às famílias com crianças e adolescentes vítimas de abuso sexual.

Para proceder com a gravação das interações busquei a autorização dos envolvidos, primeiramente explicando a pesquisa e depois solicitando a assinatura do Termo de Consentimento Livre e Esclarecido (TCLE). As crianças e adolescentes, pelo seu estatuto de dependência, precisam do consentimento do responsável para participar, mas, por problematizar ações sociais adultocêntricas e reconhecer a criança e o adolescente como sujeitos de direitos e vontades (BRASIL, 1990), também negociei com eles a obtenção da permissão, facultando-lhes sempre o direito de não aderir à pesquisa.

Por razões éticas e para garantir o anonimato dos participantes, todos os nomes de pessoas e lugares foram alterados quando da transcrição. 
Também, a pesquisa obteve aprovação pelo Comitê de Ética em Pesquisa, da Universidade do Vale do Rio dos Sinos- Unisinos.

\section{Análises}

\subsection{Produção de justificativas em interações com adolescentes}

As interações entre conselheiro tutelar e crianças e adolescentes vítimas de abuso sexual têm um formato mais ou menos padronizado de perguntas e respostas. Sendo assim, o conselheiro solicita às vítimas que narrem a sua experiência e, ao fazer isso, muitas vezes solicita accounts. O que essa seção se propõe a mostrar é como os adolescentes e as crianças menores se orientam interacionalmente frente ao paradoxo da vitimização e da culpabilização, através do provimento (ou não) de accounts (que chamo de justificativas, pois é essa a atividade majoritariamente desempenhada através dos accounts nos dados desta pesquisa).

Quando a interação envolve o tópico do abuso sexual infantil, os interlocutores se orientam constantemente para a possibilidade de serem julgados negativamente. Essa orientação tácita é que faz com que os participantes, especialmente as vítimas e seus responsáveis, se engajem em um trabalho moral defensivo, por meio da produção de justificativas.

Já a solicitação explícita de justificativas, de acordo com Robinson e Bolden (2010) e Bolden e Robinson (2011), indica que o evento a ser explicado ou justificado não está de acordo com o que é considerado pelo senso comum como apropriado. Nesse sentido, solicitar justificativas desafia os agentes da ação questionada, pois essa solicitação pode implicar julgamentos, críticas e acusações àqueles que são chamados a se justificar.

Ainda, de acordo com Boden e Robinson (2011), as solicitações de justificativas através de perguntas (normalmente as "why interrrogatives"4 , e.g. por quê, quem, onde, quando) por implicarem desalinhamento com açôes prévias (e.g. questionar os preços cobrados para o transporte do queijo), podem, se não resolvidas adequadamente na interação, ocasionar rupturas entre os interlocutores. Por serem ações despreferidas, as perguntas, geralmente, aparecem com relativo atraso no curso da interação (SCHEGLOFF, 1997).

\footnotetext{
${ }^{4} \mathrm{Nem}$ todas as perguntas com o formato de "Wh" são solicitações de justificativas (e.g. por que você não vem na minha casa hoje?) (BOLDEN; ROBINSON, 2011).
} 
Esses atrasos podem assumir o formato de silêncios, respirações, expressões de apreciação (e.g. isso foi legal de sua parte), desculpas, renúncias (e.g. eu não sei), justificativas etc. Como exceção, Robinson e Bolden (2010) apontam duas situações em que as solicitações explícitas de justificativas acontecem sem atrasos na interação: a) discussōes e b) para gerar afiliação, ao invés de desafiliação, o que acontece quando o assunto tratado é negativo e os interlocutores (que não são os agentes da ação em questão) compartilham da mesma opinião (e.g. sobre o inaceitável de uma mãe matar seus filhos).

A atribuição de responsabilidades está intrinsecamente vinculada ao conhecimento, que é também, em alguma medida, vinculado à idade das vítimas. Antes de partir para as análises das interações é importante retomar um aspecto fundamental, que é a idade das crianças vítimas de abuso sexual. Claro que esse conceito, conforme apontado por autoras como MacMartin (2002), assume dimensões elásticas e muitas vezes é usado para se ajustar aos propósitos de cada evento interacional. Contudo, há que se considerar que à medida que as crianças vão se socializando, elas vão desenvolvendo competências, inclusive sobre como se posicionar frente às diversas experiências (OCHS; CAPPS, 1996). Assim, através das narrativas, as crianças organizam e significam os eventos, especialmente os desviantes, e aprendem convenções sociais para narrar determinados aspectos desses eventos (e.g. narrar-se como uma vítima "autêntica”, ou seja, ajustar as ações àquilo que é socialmente esperado de uma vítima).

$\mathrm{O}$ excerto abaixo é parte de uma interação entre Marcos e Gabriel (16 e 14 anos respectivamente) com o conselheiro tutelar. Marcos e Gabriel acompanharam um homem estranho até a sua casa e acabaram vítimas de abuso sexual.

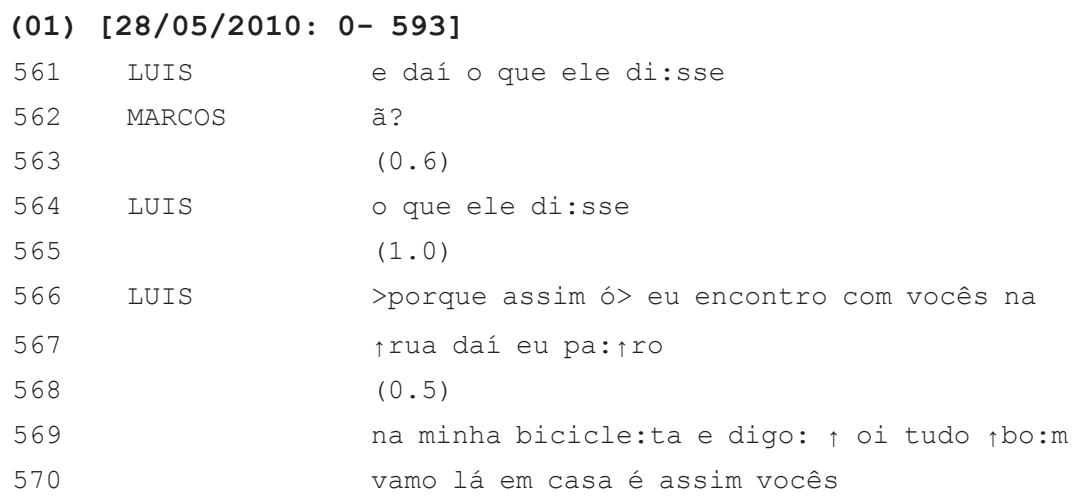




\begin{tabular}{|c|c|c|}
\hline 561 & LUIS & e daí o que ele di:sse \\
\hline 562 & MARCOS & ã? \\
\hline 563 & & $(0.6)$ \\
\hline 564 & LUIS & o que ele di:sse \\
\hline 565 & & $(1.0)$ \\
\hline 566 & LUIS & >porque assim ó> eu encontro com vocês na \\
\hline 567 & & $\uparrow r u a$ daí eu pa: $\uparrow$ ro \\
\hline 568 & & $(0.5)$ \\
\hline 569 & & na minha bicicle:ta e digo: $\uparrow$ oi tudo $\uparrow$ bo:m \\
\hline 570 & & vamo lá em casa é assim vocês \\
\hline 571 & & vão na minha casa daí ou não? \\
\hline 572 & MARCOS & não \\
\hline 573 & & $()$. \\
\hline 574 & LUIS & então o que ele di:sse vamołlá \\
\hline 575 & & $(0.7)$ \\
\hline 576 & MARCOS & ele disse: : qué dá uma ivolta \\
\hline 577 & & $(0.5)$ \\
\hline 578 & & e eu fale:i não $\uparrow$ sei $\uparrow$ aonde \\
\hline 579 & & $(2.5)$ \\
\hline 580 & & aí ele falou um negó:cio lá \\
\hline 581 & & $(1.0)$ \\
\hline 582 & & (malandrage) assim pra pegá: as mu^lhé sa:be \\
\hline 583 & LUIS & ahãm \\
\hline 584 & MARCOS & e eu pense:i †tá pegá as mulhé sabe \\
\hline 585 & & daí eu: não sabia de †nada \\
\hline 586 & & $(0.8)$ \\
\hline 587 & & daí ele chegou lá e falou que outra †coisa \\
\hline 588 & & sa:be \\
\hline 589 & & $(0.4)$ \\
\hline 590 & & daí: ele falou que: outra $\uparrow$ coisa que ia dá \\
\hline 591 & & dinhe:iro sabe \\
\hline 592 & & $(0.4)$ \\
\hline 593 & & e eu não queri:a fazê \\
\hline 594 & & $(0.4)$ \\
\hline 595 & & não queria se ensina: do sabê \\
\hline & LUIS & ahã :m \\
\hline & MARCOS & daí ele ensinô: nóis \\
\hline
\end{tabular}


O conselheiro tutelar investiga a possibilidade de os dois irmãos terem sido vítimas de abuso. Após uma longa investida interacional e depois de o conselheiro ter mencionado a "psicóloga" e os "policiais" como possíveis futuros interlocutores (não participantes no momento), os adolescentes resolvem falar do abuso sofrido.

$\mathrm{Na}$ linha 561 o conselheiro investiga que tipo de argumento o abusador teria utilizado para convencer os adolescentes a acompanhá-lo até a sua casa. A produção de um "â?" (linha 562) indica uma iniciação de reparo, indicando problemas de produção, escuta ou entendimento.

A pergunta do conselheiro (linha 561) é uma solicitação de informação e, poder-se ia especular, de uma justificativa (i.e. das razôes de acompanhar um homem estranho até a sua casa), mas Marcos não toma o turno imediatamente após essa solicitação. De acordo com Robinson e Bolden (2010), quando a justificativa solicitada não é produzida na segunda parte do par (nesse caso, Marcos), o primeiro falante do par (nesse caso, o conselheiro) frequentemente demora mais do que o tempo usual de uma transição de turnos, provocando um silêncio antes de retomar o turno (linha 563).

Após uma segunda investida (linha 564), seguida de um silêncio (linha 565), o conselheiro repete a pergunta pela terceira vez, trazendo elementos hipotéticos que culminam com a pergunta polar "vamo lá em casa é assim vocês vão na minha casa daí, ou não?” (linhas 570 e 571). A pergunta polar (HERITAGE; RAYMOND, 2012) exerce um controle maior sobre o respondente, ao impor as proposições do conselheiro (i.e. de que ninguém acompanha um desconhecido só porque ele diz "vamo lá em casa”). De acordo com Bolden e Robinson (2011), perguntas com formato negativo podem ser uma prática de formular algo ou alguém como um erro, o que pode, por si só, significar uma crítica. Nesse caso, Marcos se orienta para a iminência de uma crítica e provê a resposta preferida à pergunta polar, que é "não" (linha 572).

$\mathrm{Na}$ linha 574, após ser questionado pela quarta vez, e após mais um silêncio (linha 575), Marcos começa a explicar, em forma de discurso reportado, o motivo de terem acompanhado o abusador (linhas 576 a 582). Na sua elaboração, Marcos se orienta para a delicadeza do tópico ao produzir alongamentos (linhas 576, 578, 580 e 582) e silêncios (linhas 577, 579 e 581) e ainda trazer elementos que podem ser entendidos como não conflitantes com a ordem moral local: "dar uma volta" (linha 576) e "pegar mulher" (linha 582). "Pegar mulher" é uma ação que não traz maiores prejuízos morais, possivelmente por estar alinhada com as expectativas do "mercado heterossexual" (CAMERON, 2005). Ao construir uma explicação 
para resolver o problema de "acompanhar um homem estranho", Marcos busca um recibo do conselheiro por meio do uso do item lexical "sabe" em tom de voz ascendente (linha 582).

É interessante notar, ainda, que Marcos descreve a ação de "pegar mulher" como "malandrage" (linha 582), o que também não representa nenhum conflito para o adolescente, que pode estar demonstrando seu conhecimento de mundo sobre a "normalidade" de os "meninos fazerem malandragens". Para os estudos de gênero, caberia uma investigação se essa ordem moral local que isenta os meninos de julgamentos negativos se aplicaria também às meninas. Investigações dessa natureza, conforme nos mostra Stokoe (2003), possibilitam ver como os membros mantêm discursos ou repertórios do senso comum que "dão forma ao mundo generificado" (p. 339).

$\mathrm{Na}$ linha 584, após o recibo do conselheiro (linha 583), Marcos prossegue a sua narrativa produzindo o item lexical "tá" que nessa sequência pode ser equiparado a um "ok" ou "tudo bem", reafirmando que "pegar mulher" não representa nenhum conflito para ele. Em seguida, Marcos busca novamente um recibo do conselheiro com o item lexical "sabe" (linha 584), sem, contudo, obter sucesso.

$\mathrm{Na}$ linha 585, Marcos começa a produzir uma justificativa ao dizer que não sabia de nada, inoculando-se, desde já, de julgamentos negativos ao se indexicalizar como "aquele que não sabia". Marcos lança mão desse desconhecimento ainda nas linhas 593 e 595, desonerando-se da responsabilidade da ação decorrente (SCOTT; LYMAN, 1990). O adolescente continua buscando um recibo do conselheiro ao produzir novamente o item lexical "sabe" (linhas 588 e 591), sem lograr êxito. É interessante notar que Marcos se orienta para o tópico como delicado ao escolher a forma lexical alternativa "outra coisa" (linha 587 e 590) para se referir ao abuso. O adolescente ainda produz alongamentos em sua fala $(585,588,590,591,593 \mathrm{e}$ 595) e silêncios (linhas 586, 589, 592 e 594), além de demandar vários turnos para elaborar a sua explicação (linha 585 a 595). O elemento dinheiro (linha 591) também é trazido à fala pelo adolescente como uma justificativa, pois, de acordo com a incursão etnográfica realizada no período desta pesquisa, a família de Marcos e Gabriel vive em situação de extrema pobreza.

Como vimos, Marcos está engajado ativamente na restauração do desequilíbrio moral instaurado na interação. Ele provê justificativas para

${ }^{5}$ Saber 
realinhar as expectativas quebradas para a ação problemática de acompanhar um homem estranho (e.g. pegar mulher). Geralmente as crianças são orientadas pelo pai e pela mãe a não aceitarem nada de pessoas estranhas, não conversarem com elas e, menos ainda, acompanhá-las. Interessante, contudo, é notar que depois da justificativa solicitada, Marcos produz outras justificativas não sequencialmente relevantes, que funcionam como um trabalho moral defensivo (e.g. "eu não sabia de nada", "eu não queria sabê", "não queria se ensinado, sabê").

A justificativa não sequencialmente relevante "não queria ser ensinado, sabê"5 (linha 595) marca uma transição importante entre o desconhecimento (que desonera de responsabilidades) e o conhecimento (que traz responsabilidades). $\mathrm{O}$ apelo da aquisição involuntária do conhecimento pode ser uma estratégia de Marcos para minimizar a sua responsabilidade pelo abuso imputado ao irmão menor (Marcos fora denunciado pelos vizinhos por violência sexual contra o irmão de seis anos). Ao alegar um aprendizado "forçado", o adolescente busca minimizar a responsabilidade, atribuindo-a a uma terceira pessoa (SCOTT; LYMAN, 1990). De acordo com De Fina (2009) as formulações negativas (e.g. "eu não queria fazê" e "não queria ser ensinado"), são produzidas quando existem pressuposiçóes sobre as expectativas do interlocutor (nesse caso, o conselheiro tutelar). A formulação negativa de Marcos pode, então, ser um indicativo das pressuposiçôes do adolescente sobre a opinião do conselheiro (i.e. de que as vítimas que não mostram resistência consentem com o abuso sofrido). Isso porque, como aponta Van de Mieroop (2011), o interlocutor de maior poder interacional é normalmente visto como um potencial representante das opiniōes negativas do senso comum.

De acordo com Ostermann e Carvalho (2012), as justificativas sequencialmente não relevantes (i.e. não foram solicitadas e não têm relação direta com a ação que está sendo realizada pelos interlocutores), se reportam a questôes de outra ordem. Nesse caso, Marcos parece estar realizando um trabalho moral defensivo para "justificar" o abuso que cometeu contra o irmão, atribuindo a responsabilidade de sua ação a um terceiro, que "ensino nóis"6 (linha 597).

O próximo excerto faz parte da interação entre o conselheiro tutelar e uma adolescente de 16 anos, que vinha sofrendo abusos do padrasto desde os 10 anos de idade. Quando ela reportou o abuso, a mãe a expulsou de casa.

${ }^{6}$ Nos ensinou. 
Na psicóloga eu falo a respeito disso e muitas coisas, sobre o que eu tô sentindo, sobre as minhas emoções, essas coisa psicológica. Meu padrasto mandou minha mãe escolher entre eu ou ele. Ela sabia de tudo desde o começo e não fez nada, ela até disse que ele tava me olhando de um jeito diferente. Ela fez a escolha dela, ela disse que eu podia ir embora, aí eu saí de casa. Tenho muita saudade dos meus irmãos. (Nota de Campo: 05/07/2010)

\begin{tabular}{|c|c|c|}
\hline 175 & LUIS & . h e que ti:po de coisa que ele te fala:va \\
\hline 176 & & assim \\
\hline 177 & & $(1.0)$ \\
\hline 178 & MIRNA & ele dizia que ia me batê:, que não sei o \\
\hline 79 & & quê, que mea- me ameałçando sempre de batê \\
\hline 180 & & sałbe assi:m que nem quando eu ficava \\
\hline 181 & & sozinha com ele eu não ficava lá de:ntro eu \\
\hline 182 & & sempre ia. hh (0.8) conversá com as vizinha \\
\hline 183 & & $()$. \\
\hline 184 & LUIS & mhm (tu tinha alguma pessoa perto) \\
\hline 185 & MIRNA & ti:nha.h e ele sabi:a di:sso .hh \\
\hline 186 & & porque vivia falando $\uparrow a$ eu não vô fazê \\
\hline 187 & & na:da pra ti não sei o quê: sabe mas eu \\
\hline 188 & & †se:i que ele fica falando isso pra eu \\
\hline 18 & & fiłcá lá dentro sabe mas eu não iia ficá \\
\hline 1 & & $()$. \\
\hline & LUIS & ahãm \\
\hline & & $(0.4)$ \\
\hline
\end{tabular}

O conselheiro começa, na linha 175, perguntando sobre o que o padrasto dizia à adolescente. Mirna traz o elemento da ameaça (linhas 178 e 179) e busca um recibo do conselheiro, ao prover o item lexical "sabe" (linha 180). Imediatamente após prover a resposta solicitada pelo conselheiro, Mirna produz um relato, não solicitado pelo interlocutor, que é o fato de nunca ter ficado sozinha com o padrasto (linhas 180 a 182). Mirna pode estar se orientando para o fenômeno social da classificação das vítimas que não reportam o abuso sofrido como sendo "não autênticas", conforme mostram os estudos de MacMartin (2002), que analisou a construção de discursos jurídicos, na corte canadense.

O relato reforça a construção identitária de Mirna como uma vítima "autêntica", que oferecia resistência e que não ficava sozinha com o abusador. 
Contudo, ao passo que se constrói como uma vítima resistente, ela se indexicaliza como "aquela que sabe" e esse conhecimento vem carregado de conotações morais, como já vimos anteriormente. De acordo com as práticas socialmente compartilhadas, espera-se que as vítimas que sabem que a ação sofrida é transgressora, além de oferecerem resistência, denunciem o abuso. Como Mirna demorou seis anos para fazer a denúncia, ela, possivelmente, equaciona esse desequilíbrio moral na interação ressaltando a sua resistência.

$\mathrm{Na}$ linha 184 o conselheiro produz um " $\mathrm{mhm}$ ", indicando, neste caso, escuta ativa (HUTCHBY, 2005) e faz, em seguida, uma formulação dos turnos de fala de Mirna "tu tinha alguma pessoa por perto" (linha 184). Mirna confirma essa formulação e continua imediatamente na sua construção de vítima que ofereceu resistência, orientando-se para a inoculação de julgamentos morais depreciativos. Em discurso reportado, Mirna descreve como o padrasto tentava convencê-la a ficar dentro de casa e como ela entendia esses argumentos como estratégias para enganá-la (linha 189).

Nesse contexto, então, Mirna está realizando um trabalho interacional moral, cuja função se torna importante para análise. Conforme visto anteriormente, os adolescentes já são mais proficientes nas "linguagens morais" socialmente aprovadas e, ao se orientar para essas linguagens, elas demonstram ser participantes legítimas das suas comunidades de prática (WENGER, 1998; OCHS, 2002). Dessa forma, ao se construir como "vítima autêntica", Mirna demonstra um entendimento elaborado da ordem social.

A ordem moral funciona como um roteiro de significação das experiências humanas e ela é aprendida nos diferentes contextos sociais. À medida que se socializam, as crianças vão aprendendo a se movimentar de acordo com expectativas morais, socialmente compartilhadas. Sendo assim, Mirna demonstra possuir elementos sociais e morais suficientes para se construir como uma vítima não repreensível. A construção da identidade de vítima, assim como qualquer outra performance identitária, deve ser entendida como um construto social que emerge na interação e que é altamente negociada com o interlocutor. Assim, Mirna ao produzir justificativas, se orienta para a tendência do senso comum de corresponsabilizar as vítimas pelo abuso sofrido e se protege de inferências negativas por parte do conselheiro tutelar. 


\subsection{Produção de justificativas nas interações com crianças menores}

Contrariamente ao que pudemos ver nas interações entre conselheiro tutelar e adolescentes, as crianças menores dificilmente produzem justificativas quando respondem às perguntas sobre o abuso sofrido. Para entender melhor este fenômeno, trago, a seguir, a interação entre o conselheiro tutelar e uma criança de três anos de idade, que fora vitimizada pelo tio paterno. O tio, que tinha 14 anos à época, morava na casa do menino durante o período em que ocorriam os abusos.

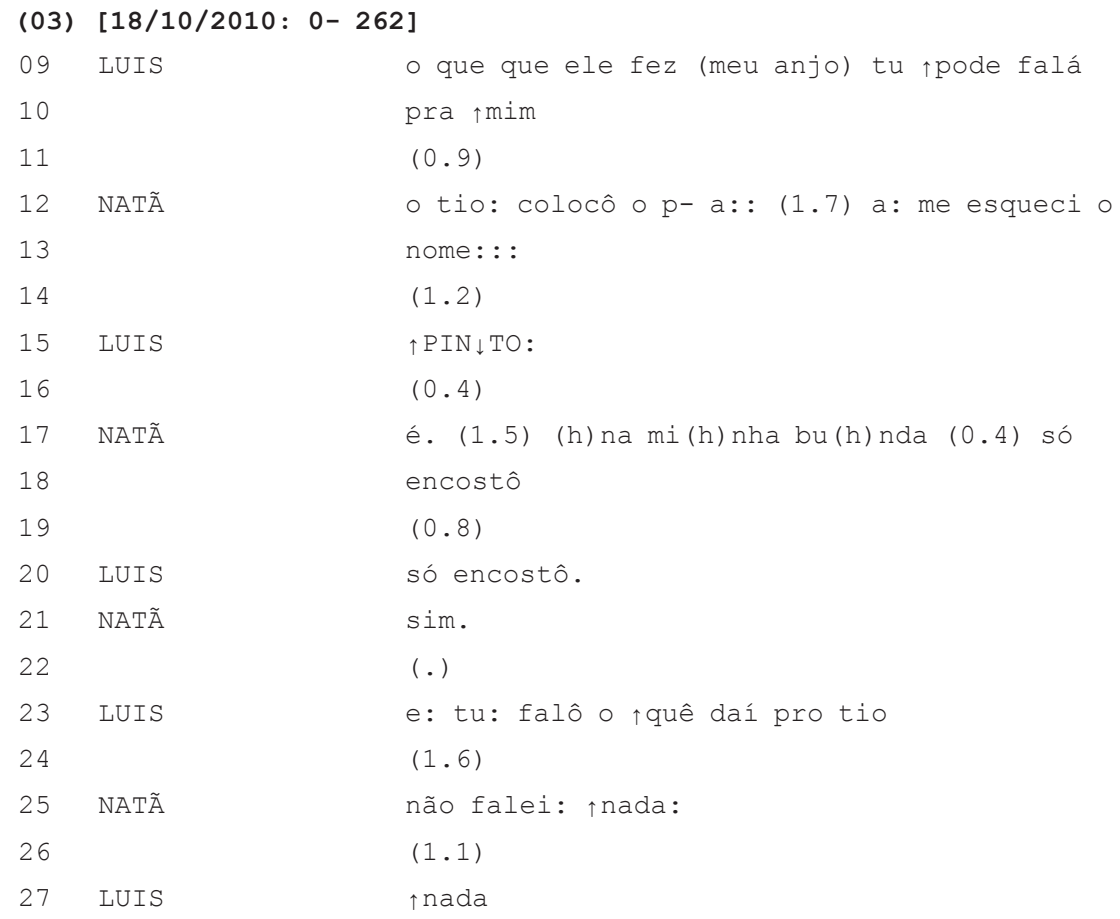

O conselheiro encoraja Natã a narrar o que aconteceu (linhas 09 e 10) e, ao fazer isso, ele busca construir uma relação afetiva, de adulto para criança, usando a expressão "meu anjo" (linha 09). Após um silêncio, Natã começa a dizer o que houve, mas demonstra não ter conhecimento lexical suficiente para nomear um elemento (linha 12). O conselheiro fornece, então, o item lexical que o menino buscava: "pinto" (linha 15). Natã confirma a oferta lexical e traz um fato adicional de que o tio "só encostô". O fato de o menino mencionar que o tio "só encostou" o pinto poderia ser entendido 
como uma justificativa que realiza o trabalho de deixar claro que "não houve penetração". Contudo, o menino pode ter trazido esse elemento à fala por ter sido exposto a exames médicos e por ter ficado bem estabelecido que não houve penetração. Ainda, conforme atestam os registros etnográficos, os pais de Natã repetiam a todo o momento que "graças a deus o tio só encostou o pinto".

Essa sensação de alívio da família e a constante reafirmação de que o tio "só encostô" pode ser uma mensagem para Natã de que é desejável que ele diga que o tio "só encostô o pinto", o que se poderia analisar como uma socialização nas preferências de relatar um evento (OCHS, 2002). Ainda, a família é o primeiro reduto em que as crianças aprendem como é desejável tratar as pessoas, construir relacionamentos sociais, performar identidades e, ao mesmo tempo, "como devem apreender e criativamente reconfigurar objetos no mundo" (OCHS; KREMER-SADLIK, 2007, p. 5). Da mesma forma, o aprendizado moral se dá nas práticas familiares cotidianas, pois interações que envolvem crianças e adultos estão imbuídas de "mensagens implícitas e explícitas de certo e errado, melhor e pior, normas, regras, obrigações, deveres, etiquetas, raciocínio moral, virtude, caráter e outras dimensões para conduzir a uma vida moral" (OCHS; KREMER-SADLIK, 2007, p. 5). Assim, concepçōes morais de "bom" saturam a vida cotidiana das famílias, corroborando a ideia de MacIntyre (1984, apud OCHS; KREMER-SADLICK, 2007, p. 9) de que "virtude é intrínseca à prática".

$\mathrm{Na}$ linha 20 o conselheiro repete a fala de Natã em tom ascendente (i.e. de pergunta) "só encostou" e o menino confirma. Depois de esclarecidos os fatos, o conselheiro faz investigações adicionais que dizem respeito às reações da vítima. Na linha 23, por exemplo, solicita a informação "tu falô o que daí pro tio". A resposta de Natã, sem a produção de nenhuma justificativa (linha 25) parece frustrar as expectativas do conselheiro, que repete a fala do menino com ascendência na entonação, "nada" (linha 27). Contrariamente ao que vimos nas interaçôes com adolescentes, eles normalmente estão atentos aos possíveis julgamentos negativos e produzem justificativas para explicar, por exemplo, o silêncio sobre o abuso.

A solicitação da informação pelo conselheiro pode ser uma possível orientação do profissional para o fato de que as vítimas deveriam dizer algo para seus agressores. Pelo fato de Natã não ter tomado essa solicitação de

${ }^{7}$ As expressões entre aspas referem-se a falas reportadas pelo pai da Gabi. 
informação como moralmente implicativa, podemos inferir que o menino não tem recursos sociais suficientes para significar a ação como moral, ou seja, ele ainda não foi plenamente socializado para performar o papel de "vítima ideal".

O próximo excerto foi retirado da interação entre o conselheiro tutelar e uma menina de seis anos (Gabi), que sofria abusos pelo tio paterno, que morava na mesma residência. A menina contara sobre as "brincadeiras de namorado" com o tio para a sua babá, pois "confiava bastante nela” . A babá contou para os pais e esses, por conseguinte, acionaram o Conselho Tutelar, a polícia e uma psicóloga.

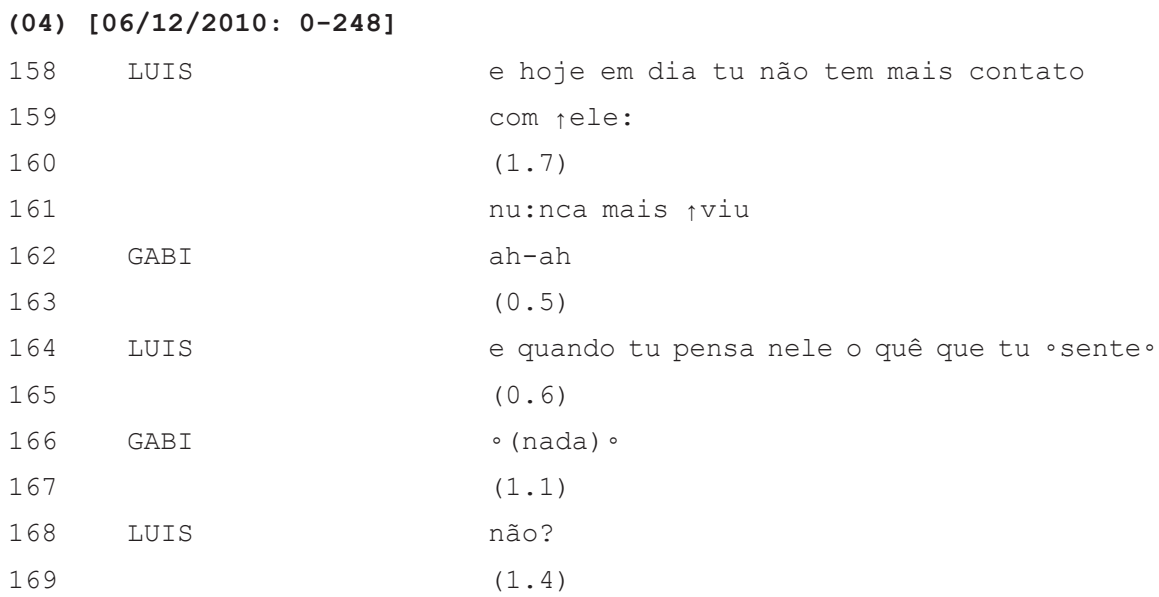

Depois de estabelecidos os fatos e esclarecidas as circunstâncias do abuso, o conselheiro pergunta, na linha 158 e 159, se Gabi ainda tem contato com o tio. Após um silêncio (linha 160), o conselheiro reformula a pergunta "nunca mais viu" (linha 161). Após a confirmação de Gabi, um novo silêncio se instaura e o conselheiro toma o turno para investigar os "sentimentos" de Gabi em relação ao tio (linha 164). O conselheiro constantemente se orienta para a necessidade de significar as experiências das vítimas e se engaja ativamente nessa tarefa, oferecendo, inclusive, qualificadores para as crianças. Esses qualificadores funcionam, muitas vezes, como roteiros de significaçôes para as vítimas, que vão sendo socializadas sobre como performar a identidade socialmente ratificada de vítima.

Gabi responde, em volume de voz baixo, que não sente nada pelo tio (linha 166), não reconhecendo essa solicitação como moralmente implicativa. 
O conselheiro reage com surpresa à resposta de Gabi, ao repetir a negativa da menina com ascendência na entonação (linha 168). Essa reação de surpresa demonstra uma possível orientação do conselheiro para o fato de que é esperado que as vítimas sintam algo pelo abusador, de preferência algo negativo.

\section{Considerações}

Como vimos até aqui, crianças e adolescentes respondem de maneira diferente às solicitações de informações, explicações e motivos. As crianças menores pouco se engajam em atividades morais, enquanto as maiores desempenham um papel ativo no trabalho de gerenciamento da face, por meio do provimento de justificativas. A principal rota analítica que proponho, através da análise das interações entre conselheiro tutelar e crianças e adolescentes vítimas de abuso sexual, é que a significação da experiência passa necessariamente pela esfera interacional. Ou seja, à medida que as crianças vão se socializando, e esse processo se estende por toda a vida (SCHIEFFELIN; OCHS, 1986; OCHS; KREMER-SADLIK, 2007; OCHS, 1993; 1996; OCHS; CAPPS, 1996; 1997), elas vão aprendendo a se alinhar com as expectativas morais e sociais. Nesse sentido, ao tornar as regras sociais inteligíveis na interação, o próprio conselheiro tutelar acaba instrumentalizando as crianças com elementos de socialização e rotas de significação da experiência do abuso.

É fundamental ressaltar sempre que, por mais assimétricas que as interações possam ser, as crianças não são receptoras passivas da cultura: elas exercem agentividade ao contribuírem nos processos de significação, além de coconstruírem a própria organização interacional com seus interlocutores/as (i.e. elas preenchem as expectativas estruturais da interação). A ação de narrar é, via de regra, uma atividade que apresenta uma estrutura mais assimétrica, pois um dos interlocutores retém o turno de fala por mais tempo e é responsável por conduzir a atividade. No caso desta pesquisa, pudemos observar que o conselheiro assume um papel bastante ativo na construção das narrativas, determinando, muitas vezes, os contornos dessa ação (e.g. ao oferecer qualificadores para as vítimas descreverem seus sentimentos). Essa participação ativa do conselheiro está ligada ao seu objetivo interacional, que é o de investigar e apurar detalhes do abuso para construir um relato convincente para o sistema judiciário (e.g. Promotoria da Infância e da Juventude, Ministério Público) e, consequentemente, conseguir justiça para as vítimas. 
Conforme discutimos ao longo deste artigo, a produção de justificativas é uma estratégia linguístico-discursiva empregada pelos falantes para restabelecer a normalidade de eventos desviantes (e.g. abuso sexual). A produção de justificativas posiciona os interlocutores como agentes morais, atentos ao princípio básico da moralidade que é a reciprocidade de expectativas (BERGMANN, 1988). De acordo com esse princípio, os agentes são mutuamente responsabilizados pelas suas açôes e, caso essas ações estejam em desacordo com as convenções morais e sociais, é esperado que o agente restaure, no curso da interação, essa quebra de expectativas. Assim, quando Marcos é questionado por ter acompanhado um homem estranho, ele se orienta para a quebra de expectativas dessa ação e se engaja no provimento de justificativas (e.g. dar uma volta, pegar mulher). Ao prover essas justificativas, Marcos demonstra conhecimento das normas morais (i.e. de que não se acompanha homens estranhos), e se orienta para a necessidade de construir-se como moralmente aceitável.

De acordo com o que vimos, os adolescentes demonstram maior socialização nas normas morais e sociais do que as crianças menores. Essas últimas não se engajam na ação de prover justificativas e se orientam menos para a necessidade de se construírem como agentes morais (e.g. quando Gabi diz não sentir nada pelo abusador e Natã revela não ter dito nada ao abusador). A reconstrução da narrativa com o conselheiro tutelar é, assim, um espaço de socialização sobre como as crianças devem se posicionar frente ao abuso sofrido, sobre como devem narrar a experiência, o que devem sentir e pensar. As práticas narrativas dão forma às experiências das crianças, além de trazerem para a superfície da fala noções do senso comum sobre infância, ordem social moral e abuso sexual.

\section{Referências}

ALMEIDA, A. A construção da masculinidade na fala-em-interação em cenários escolares. 2009. 298 f. Tese (Doutorado em Linguística Aplicada)- Instituto de Letras. Universidade Federal do Rio Grande do Sul, Porto Alegre, 2009.

ARUNDALE, R. Constituting face in conversation: face, facework and interactional achievement. In: Journal of Pragmatics. v. 35, p. 1453-1469, 2010.

ARUNDALE, R. Face as relational and interactional: A communication framework for research on face, facework, and politeness.In: Journal of Politeness Research. $\mathrm{v}$. 2, p. 193-216, 2006. 
BERGMANN, J. R. Introduction: Morality in Discourse.In: Research on Language and Social Interaction. v. 31, p. 279-294, 1998.

BERGMANN, J. R. Veiled morality: notes on discretion in psychiatry. In: DREW, P.; HERITAGE, J. (Ed.). Talk at work: Interaction in institutional settings. Cambridge, England. Cambridge University Press, 2002. p. 137-162.

BOLDEN, G.; ROBINSON. J. D. Soliciting Accounts with Why- Interrogatives in Conversation. In: Journal of Communication. v. 61, p. 94-119, 2011.

BRASIL. Lei Federal n. 8.069, de 13 de julho de 1990 (Estatuto da Criança e do Adolescente).

BUTTNY, R. Social accountability in communication. London: Sage Publications, 1993.

CAMERON, D. Language, Gender, and Sexuality: Current Issues and New Directions. In: Applied Linguistics, Oxford. v. 26, p. 482-502, 2005.

CARVALHO, T. O trabalho interacional de provimento de justificativas no disque saúde (AIDS). 2012. 98 f. Dissertação de Mestrado (Mestrado em Programa de Pós Graduação em Linguística Aplicada)- Universidade do Vale do Rio dos Sinos, 2012. COULON, A. Etnometodologia. Petrópolis: Vozes, 1995.

DE FINA, A. Narratives in interview-The case of accounts.In: Narrative Inquiry. v. 19, p. 233-258, 2009.

DEL CORONA, M. O universo do 190 pela perspectiva da fala-em-interação. 2011. 246 f. Tese de Doutorado (Doutorado em Programa de Pós Graduação em Linguística Aplicada)- Universidade do Vale do Rio dos Sinos, 2011.

DREW, P. Complaints about transgressions and misconduct. In: Research on Language and Social Interaction. Lawrence Erlbaum Associates. v. 31, p. 295-325, 1998.

FETTERMAN, D. Ethnografhy step by step. London. Sage, 1998.

FIRTH, A. 'Accounts' in negotiation discourse: A single-case analysis. In: Journal of Pragmatics. Elsevier. v.23, p. 199- 226, 1995.

GARCEZ, P. A perspectiva da análise da conversa etnometodológica sobre o uso da linguagem em interação social. In: LODER, L.; JUNG, N. (Ed.). Fala-em-interação social: introdução à análise da conversa etnometodológica. Campinas: Mercado das Letras, p.17-38, 2008.

GARFINKEL, H. Studies in ethnometodology.In: Englewood Cliffs. NJ: PrenticeHall, 1967.

GOFFMAN, E. The presentation of the Self in Everyday Life. New York: Anchor Books, 259 p., 1959.

HERITAGE, J.; RAYMOND, G. Navigating Epistemic Landscapes: Acquiescence, Agency and Resistance in Responses to Polar Questions. In: DE RUITER, J.P. (Ed.). Questions: Formal, functional and interactional perspectives. Cambridge: Cambridge University Press, p. 179-192, 2012. 
HUTCHBY, Y. Active listening: Formulations and the elicitation of feelings-talk in child counseling. In: Research on Language and Social Interaction. v. 38, n.3. p. 303-329, 2005.

JEFFERSON, G. On the organization of laughter in talk about troubles. In: ATKINSON, J. M.; HERITAGE, J. (Ed.). Structures of social action. Cambridge, 1984. p. 346-369.

LERNER, G. Finding "Face" in the Preference Structures of Talk-in-Interaction. In: Social Psychology Quarterly. v. 59, p. 303-321, 1996.

MACMARTIN, C. (Un)reasonable Doubt? The invocation of Children's Consent in Sexual Abuse Trial Judgments. In: Discourse \& Society. v. 13, p. 9- 40, 2002.

MAYNARD, D. W. Bad News, Good News. In: Conversational Order in Everyday Talk and Clinical Settings. Chicago. The University of Chicago Press, 337p., 2003. MAYNARD, D. W. Inside plea bargaining: The language of negotiation. New York: Plenum, 1984.

MILLS, W. C. Situated Actions and Vocabularies of Motive. In; American Sociological Review. v. 6, p. 904-913, 1940.

OCHS, E.; CAPPS, L. Narrating the self. Annu. In; Rev. Anthropol.v. 25 p. 19-43, 1996.

OCHS, E. Becoming a speaker of culture. In: KRAMSCH, C. (Ed.). Language Acquisicion and Language Socialization: Ecological Perspectives. London, p. 99120, 2002.

OCHS, E; CAPPS, L. Narrative Authenticity.In: Journal of Narrative and Life History. v. 7, p. 83-89, 1997.

OCHS, E. Constructing Social Identity: A Language Socialization Perspective. In; Research on Language and Social Interaction. v. 26, p. 287-306, 1993.

OCHS, E; KREMER-SADLIK, T. Introduction: morality as family practice. In: Discourse \& Society. Sage Publications, v. 18, p. 5-10, 2007.

O’REILLY, K. Key concepts in ethnography. London. Sage, 240 p., 2009.

OSTERMANN, A. C.; CARVALHO T. Comunicação Pessoal. 2012.

PSATHAS, G. Studying the Organization in Action: Membership Categorization and Interaction Analysis. In: Human Studies. Boston, v. 22, p.139-162, 1999.

ROBINSON, J. D.; BODEN, G. B. Preference organization of sequence-initiating actions: The case of explicit account solicitations.In: Discourse Studies. v. 12, n. 4, p. 501-533, 2010.

SACKS, H; SCHEGLOFF, E.; JEFFERSON, G. A Simplest Systematics for the Organization of Turn-Taking for Conversation. In: Language. v. 50, n. 4, p. 696735, 1974. 
SACKS, H. Lectures on Conversation. Oxford: Blackwell Publishers, 1992. v. I- 819 p, v. II- 580 p.

SAMRA-FREDERICKS, D. Ethnomethodology and the moral accountability of interaction: Navigating the conceptual terrain of 'face' and face-work. In: Journal of Pragmatics. v. 42, p. 2147-2157, 2010.

SANTOS, B. R. Contribuiçôes para um balanço das campanhas de combate ao abuso e exploração sexual de crianças e adolescentes no Brasil. In: LIBÓRIO, R. M. C.; SOUZA, S. G. (Ed.). A exploração sexual de crianças e adolescentes no Brasil. Reflexōes teóricas, relatos de pesquisas e intervençôes psicossociais. Casa do Psicólogo, p. 99- 147, 2003.

SCHEGLOFF, E. A. Whose Text? Whose Context? In: Discourse and society. v. 8, p. 165-187, 1997.

SCHEGLOFF, E. A. Narrative analysis 30 years later. In: Journal of Narrative and Life History. v. 7, p. 97-106, 1997.

SCHIEFFELIN, B. B; OCHS, E. Language Socialization. In: Ann. Rev. Anthropol.v.15, p. 163-191, 1986.

SCHNACK, C.; PISONI, T.; OSTERMANN, A. C. Transcrição de fala: do evento real à representação escrita. In: Entrelinhas. v. 2, p. 1-7, 2005.

SCOTT, M.; LYMAN, S. Accounts. American Sociological Review, v. 33 p. 4662, 1968. Reprinted. In: BRISSET. D.; EDGLEY C. (Ed.). Life as Theater: a Dramaturgical Sourcebook. Aldine Publishing Company, p. 219-238, 1990.

SELL, M.; OSTERMANN, A. C. Análise de Categorias de Pertença (ACP) em estudos de linguagem e gênero: A (des) construção discursiva do homogêneo masculino. Alfa, v.53, p. 11-34, 2009.1

SEMIN, G.; MANSTEAD, A. The accountability of conduct: A social psychological Review. v. 41, p. 838-849, 1983.

STIVERS, T; MONDADA, L; STEENSIG, J. The morality of knowledge in conversation. Cambridge University Press, 2011.

STOKOE, E. H. Mothers, Single Women and Sluts: Gender, Morality and Membership Categorization in Neighbour Disputes. In: Feminism \& Psycology. v. 13, p. 317-344, 2003.

TRINCH, S. Recalling rape: moving forward from what we know about rape. In: HEFFER, C.; ROCK, F.; CONLEY, J. (Ed.). Legal-Lay Communication: Textual Travels in the Law. Oxford: Oxford University Press, p. 288-305, 2013.

VAN DE MIEROOP, D. Identity negotiations in narrative accounts about poverty. In: Discourse \& Society. v.22, p. 565-591, 2011.

WENGER, E. Comunities of Practice: Learning, Meaning and Identity. New York: Cambridge University Press, 1998.336 p. 
CONVENÇÕES DE TRANSCRIÇÃO

\begin{tabular}{|r|l|}
\hline texto] & Falas sobrepostas \\
$=$ & Fala colada \\
$(1.8)$ & Pausa \\
$()$. & Micropausa \\
, & Entonação contínua \\
. & Entonação ponto final \\
$?$ & Entonação de pergunta \\
- & Interrupção abrupta da fala \\
$:$ & Alongamento de som \\
$>$ texto< & Fala mais rápida \\
$<$ texto $>$ & Fala mais lenta \\
texto $^{\circ}$ & Fala com volume mais baixo \\
TEXTO & Fala com volume mais alto \\
Texto & Sílaba, palavra ou som acentuado \\
$($ texto) & Dúvidas \\
XXXX & Texto inaudível \\
$(($ texto $))$ & Comentários da transcritora \\
$@$ @@@ & Risada \\
$\downarrow$ & Entonação descendente \\
.hhh & Entonação ascendente \\
& Inspiração audível \\
\hline
\end{tabular}

FONTE: Schnack, C.; Pisoni T.; e Ostermann, A. Transcrição de fala: do evento real à representação escrita, Entrelinhas, v. 2, n. 2. 2005.

Data de submissão: 19/09/2014. Data de aprovação: 05/12/2014. 